\title{
OPTIMALISASI PROSES INJECTION MOULDING PADA NANOALUMINA
}

\author{
MOH. JUFRI \\ Jurusan Teknik Mesin Fakultas Teknik Universitas Muhammadiyah Malang \\ E-mail: Jufri63@yahoo.com
}

\begin{abstract}
ABSTRAK
Komposit disusun dari material dengan fungsi sebagai matriks yang mempunyai karakteristik kelemahan dan material dengan fungsi pengisi yang mempunyai fungsi untuk mentransfer kekuatan dari beban di matriks untuk memberi kekuatan ke material. Plastik memiliki lebih banyak kelebihan disbanding material lain; diantaranya, dapat dibentuk dengan baik, berbobot ringan, mudah didapatkan dan harganya relative murah. Akan tetapi, masalahnya adalah filler yang digunakan masih menggunakan fiberglass yang akan mengganggu kesehatan manusia. Butiran alumina yang digunakan di sini adalah Merck dengan ukuran partikel $>0.063 \mathrm{~mm}$, untuk mendapatkan ukuran nano akan dilakukan pencampuran dengan menggunakan Mixer Ball Mill selama 50 jam dan akan diukur untuk menentukan ukuran partikel dengan Particle Size Analyzer (PSA), kemudian akan dikeringkan dalam oven dengan temperatur $80^{\circ}$ C. Prosentase dari nano alumina untuk masing-masing adalah 1\%, 2\%, 3\%, 4\%, 5\%, 6\% dan 7\%. Setelah itu, akan dicampur dengan butiran plastik PP yang akan dikonduksi dengan internal mixer to memastikan material terdistribusi merata, kemudian akan dituangkan dalam mesin cetak injeksi yang beroperasi pada temperatur $170^{\circ} \mathrm{C}$ dan diinjeksikan dalam cetakan contoh. Hasil dari karakteristik tensile strength, modulus elasticity dan tensile menunjukkan pengurangan dengan penambahan 2-3\% nano alumina pada matrik polipropilen.
\end{abstract}

Kata kunci: komposit, nanoalumina, polipropilene

\begin{abstract}
Composite is arranged from material with function as matrix that has weaker characteristic and material with filler function that has a function to transfer force from load in matrix. Plastic has more advantages than other materials; those are, able to be formed finely, light in weight, easy to get and the price is cheaper relatively. However, the problem is the filler that is involved here is still using fiberglass in which it will disturb human health. Alumina dust used here is Merck by particle size of $>0.063 \mathrm{~mm}$, to get nano size then it would be mixed by Mixer Ball Mill for 50 hours and would be measured for dust grain size with particle size analyzer (PSA), then it is dehydrated in the oven by temperature of $80^{\circ} \mathrm{C}$. The percentage of nano alumina for each are 1\%, $2 \%, 3 \%, 4 \%, 5 \%, 6 \%$ and $7 \%$. Furthermore, it is mixed with PP plastic grain that is conducted by internal mixer to ensure the material distribution evenly, then it is poured in hoper in injection moulding machine that is operated in the temperature of $170^{\circ} \mathrm{C}$ and is injected in sample test moulding. The result of characterization of tensile strength, modulus elasticity and tensile show the decrement by addition of 2-3\% of nano alumina in polypropylene matrix.
\end{abstract}

Key words : composite, nanoalumina, polypropylenee

\section{PENDAHULUAN}

Strategi pengembangan nanoteknologi pada masing-masing negara umumnya mengacu pada kompetensi negaranya. Dalam kenyataanya, Indonesia memiliki keunggulan kompetitif yang berupa kekayaan sumber daya alam baik berupa mineral pasir besi, kuarsa, alumina, tembaga, emas dan lain-lain (www.indonetwork.co.id/sell/ kimia/0.html). Di Jawa Timur pada wilayah utara dan selatan dikelilingi oleh pegunungan kapur yang memproduksi sumber daya alam baik berupa mineral pasir besi, kuarsa, alumina, tembaga, emas dan lain-lain. Alumina $\left(\mathrm{Al}_{2} \mathrm{O}_{3}\right)$ termasuk mineralogi batuan yang prosentase kandungannya nomor dua $(15,01 \%)$ setelah pasir silika/ $\mathrm{SiO}_{2}(69,39)$ dan alumina $\left(\mathrm{Al}_{2} \mathrm{O}_{3}\right)$ produk lokal diekspor dalam bentuk bauksit dengan nilai eksportnya 15 juta US $\$$ sedangkan nilai importnya setelah diolah menjadi alumina analis dan teknis harganya menjadi 2000 kali lipat (Edy D, 1996).

Namun, sumber daya tersebut masih belum banyak diberikan nilai tambah sehingga belum dapat dijadikan sebagai penentu daya saing bangsa. Pemanfaatan sumber daya alam tersebut baru 
berupa eksploitasi dengan kuantitas yang besar dan belum banyak diolah sehingga masih bernilai sangat rendah. Oleh karena itu, pengembangan nanoteknologi harus dapat diarahkan untuk mengolah dan memberikan penambahan nilai secara signifikan bagi sumber daya alam Indonesia sehingga dapat meningkatkan daya saing bangsa (Nurul T, 2006). Limbah Plastik dapat dimanfaatkan untuk aplikasi bahan teknik (Hajrianto, Feri F.,2005) dan dipilihnya plastik polypropylene oleh pendesaim material karena dapat menghasilkan sifat gabungan yang tidak mungkin diperoleh pada jenis bahan lain seperti ringan, tangguh, tahan korosi, warna tahan lama, transparan, mudah pemrosesannya (Hosen J., 2001). Pada penelitian ini matriks yang digunakan yaitu matriks polimer jenis polypropelene daur ulang. Polypropylene merupakan jenis plastic yang sulit terdegradasi.

Dari suatu pengamatan bahwa polipropelen yang berperan sebagai compatibilizer didalam komposit terlokalisir pada interface yang merupakan filler dan matrik polimer sehingga meningkatkan adhesi antara 2 bagian tersebut. Ikatan kimia antara polipropelene yang terbentuk akan berperan penting dalam meningkatkan sifat mekanika komposit. Polypropylene dapat dihasilkan dengan keteraturan tinggi dalam konfigurasi polimernya. Polypropylene adalah suatu material hemat yang menawarkan suatu kombinasi antara, bahan kimia, mekanik, kekayaan elektrik dan yang berkenaan dengan panas yang tidak ditemukan pada termo-plastik lain. Polypropylene mempunyai kelebihan di mana tahan terhadap temperatur tinggi dan memiliki elastisitas. Polypropylene memiliki sifat mampu larut dalam organik, degreasing agen dan electrolytic menyerang. Dalam penelitian ini, nano alumina dipilih sebagai filler karena sifat kombinasi kimiawi dan fisiknya yang istimewa seperti ketahanan pada panas dan wear, kekuatan spesifik yang tinggi dan ketahanan oksidasi yang baik.

\section{METODE}

Karakterisasi sampel sebagai bahan baku pembuatan panel komposit berbasis polimer berbentuk bijik plastik jenis polypropylene (PP) yang diperkuat dengan serbuk nano alumina. Serbuk alumina yang digunakan merek Merck dengan ukuran partikel $>0.063 \mathrm{~mm}$, untuk mendapatkan ukuran nano kemudian di Mixer Ball Mill selama 50 jam dan dilakukan pengukuran besar butir serbuk dengan particle size alnalyser (PSA) dan dikeringkan di dalam oven pada suhu $80^{\circ} \mathrm{C}$. Prosentase nanoalumina masing-masing $1 \%, 2 \%$, $3 \%, 4 \%, 5 \%, 6 \%$ dan $7 \%$ selanjutnya dicampur dengan bijih plastik jenis PP dilakukan oleh internal mixer untuk memastikan pemerataan material, kemudian dituangkan kedalam hoper pada mesin injection moulding yang diopersikan pada suhu $170^{\circ} \mathrm{C}$ dan diinjeksikan kedalam cetakan sampel uji yang telah disiapkan. Pengujian dilakukan sesuai standar ASTM D 638 dengan menggunakan Universal Testing Maching 4302. Langkah selanjutnya melakukan karakterisasi terhadap kekuatan tarik, modulus elastisitas dan elongasi dari sampel.

\section{HASIL DAN PEMBAHASAN}

Hasil penelitian terhadap karakteristik sifat mekanik yang meliputi kekuatan tarik, modulus young (elastisitas) dan elongasi/peregangan dengan penambahan nano alumina $\left(\mathrm{Al}_{2} \mathrm{O}_{3}\right)$ masing-masing 1,2,3,4,5,6 dan $7 \%$ pada bijih plastik polypropylene. Dengan bertambahnya prosentase kandungan nanoalumina pada bijih plastik polypropylene, maka kekuatan tarik nanokomposit akan menurun sampai dengan $2 \%$ dan kemudian meningkat setelah di atas $2.0 \%$ (gambar 1). Kekuatan tarik menurun dengan bertambahnya prosentase kandungan alumina karena ikatan antar muka yang lemah yang menciptakan jarak mikro yang terpisah secara parsial antara filler dan matrik polimer akan menghalangi perkembangan tekanan ketika tekanan tarik diberikan karena matrik mempunyai interaksi yang lemah (Yang, H.S. dkk, 2004).

Dari gambar 1 dan 2 terlihat bahwa penurunan nilai kekuatan tarik dan modulus elastisitas nanokomposit dengan penambahan prosentase alumina terhadap bijih plastitik polypropylene disebabkan partikel nano mudah menyebabkan formasi pengelompokkan filler dalam badan matrik yang kemudian akan menyebabkan kegagalan pada bagian tertentu yang bisa menyebarkan keretakan atau patah. Akibatnya, akan menyebabkan penurunan

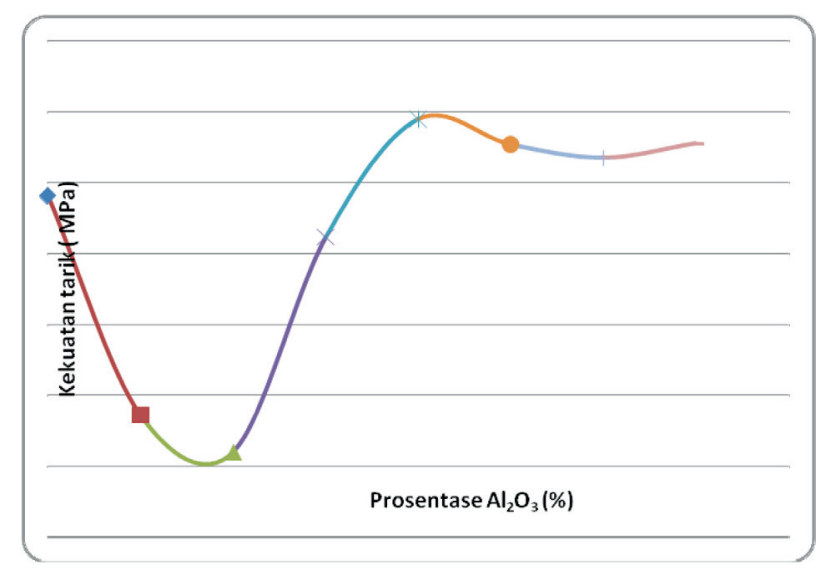

Gambar 1. Kekuatan tarik nanokomposit penguat $\mathrm{Al}_{2} \mathrm{O}_{3}$ matrik bijik plastik polypropylene hasil daur ulang dengan prosentase berbeda. 


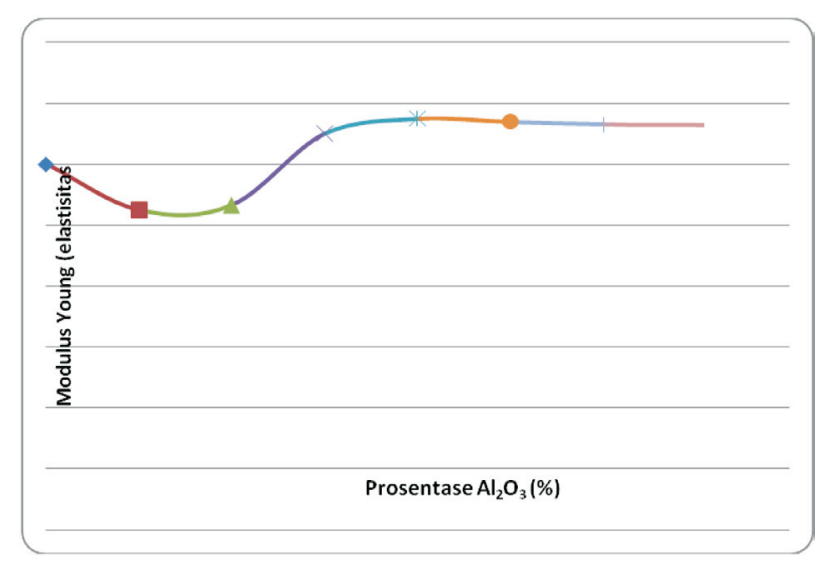

Gambar 2. Modulus elastisitas (Young) nanokomposit penguat $\mathrm{Al}_{2} \mathrm{O}_{3}$ matrik bijik plastik polypropylene hasil daur ulang dengan prosentase berbeda.

nilai kekuatan tarik. Permukaan partikel nano $\mathrm{Al}_{2} \mathrm{O}_{3}$ adalah polar dan polypropylene adalah non polar sehingga dengan tambahan nano $\mathrm{Al}_{2} \mathrm{O}_{3}$ pada matrik polypropylene, permukaan antara keduanya akan menjadi tidak menyatu. Dengan kata lain, kekuatan dan modulus komposit tidak bisa lebih besar daripada modulus yang tidak mengandung penguat(filler), karena partikel filler tidak bisa menghasilkan fraksi ekstra dari beban eksternal (Wu, 2002). Adapun pada Gambar 2 menunjukkan nilai modulus elastisitas (young) mengalami penurunan di bawah $1 \%$ dengan bertambahnya prosentase nanoalumina dan mengalami peningkatan di atas $2 \%$.

Polypropylene mempunyai sifat sangat kaku; berat jenis rendah, tahan terhadap bahan kimia, asam, basa, tahan terhadap panas, dan tidak mudah retak. Plastik polypropylene digunakan untuk membuat alat-alat rumah sakit, komponen mesin cuci, komponen mobil, pembungkus tekstil, botol, permadani, tali plastik., sedangkan fungsi alumina sebagai filler sebagai penopang kekuatan dari komposit, sehingga tinggi rendahnya kekuatan komposit sangat tergantung dari filler yang digunakan, karena tegangan yang dikenakan pada komposit mulanya diterima oleh matrik akan diteruskan kepada filler, sehingga serat akan menahan beban sampai beban maksimum. Oleh karena itu serat harus mempunyai tegangan tarik dan modulus elastisitas yang lebih tinggi daripada matrik penyusun komposit. Di antara berbagai jenis polimer termoplastik, polypropylene merupakan salah satu jenis plastik yang paling luas penggunaannya, khususnya dalam bidang otomotif, listrik, pengemas, kontainer/botol dan berbagai aplikasi konsumen lainnya. Alasannya dapat ditemukan pada sifatsifat polypropylene yang ringan, mudah diproses, temperatur panas distorsi yang mencapai di atas $100^{\circ} \mathrm{C}$, dan memiliki ketahanan kimia maupun mekanik yang bagus. Evaluasi ketahanan kimia pada polypropylene komersial yang telah membuktikan bahwa kekuatan mekanik polypropylene tidak mengalami perubahan yang signifikan ketika didegradasi dalam berbagai jenis bahan kimia, yaitu air, garam, asam dan bahan bakar diesel (solar) selama waktu degadrasi hingga 1000 jam. Plastik polypropylene merupakan salah satu jenis polimer yang sering dimodifikasi dan ditingkatkan performanya, yaitu dengan menambahkan filler atau zat aditif lain ke dalam matriks sehingga menghasilkan material baru komposit plastik polypropylene.

Alumina sebagai penguat dalam komposit memiliki ikatan antar atom pada alumina merupakan ionic bonding yang kuat sehingga tetap stabil walaupun pada temperatur yang sangat tinggi karena membentuk fasa kristal heksagonal alpha ( $\alpha$-hexagonal) yang sangat stabil. Pada oksida keramik, fasa ini merupakan yang paling kuat dan kaku. Lebih lanjut, fasa ini memiliki kekerasan tinggi dan sifat dielektrik yang excellent. Alumina murni, memiliki fungsi ganda baik sebagai atmosfer pengoksidasi maupun pereduksi sampai $1925^{\circ} \mathrm{C}$. Sedangkan kehilangan berat material ini dalam ruang vakum berkisar dari $10^{-7}$ sampai $10^{-6} \mathrm{~g} /$ $\mathrm{cm}^{2}$ det di atas temperatur $1700^{\circ} \mathrm{C}$ sampai $2000^{\circ}$ C. Kemudian, alumina sangat resisten terhadap serangan segala gas kecuali fluorine, dan tahan terhadap semua reagen terkecuali asam hydrofluoric dan phosphosric. Adapun serangan pada suhu tinggi, alumina dengan kemurnian rendah, mudah diserang oleh partikulat gas logam alkali (arumaarifu, 2010).

Berdasarkan pada Gambar 3, persentase peregangan pada patah untuk Polypropylene/ nano komposit $\mathrm{Al}_{2} \mathrm{O}_{3}$ menurun seiring dengan bertambahnya persentase nano $\mathrm{Al}_{2} \mathrm{O}_{3}$ hingga

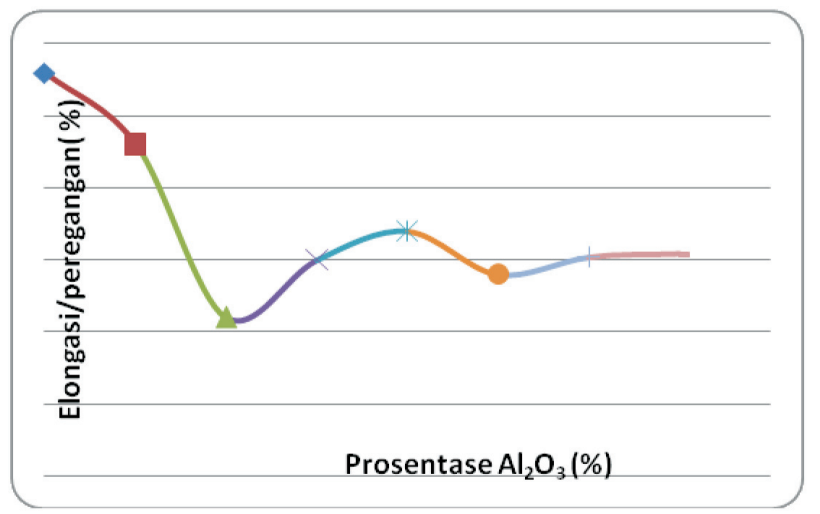

Gambar 3. Elongasi/peregangan(\%) nanokomposit penguat $\mathrm{Al}_{2} \mathrm{O}_{3}$ matrik bijik plastik polypropylene hasil daur ulang dengan prosentase berbeda 
2 wt\% dan kemudian meningkat hingga 3 sampai 7 wt\% nano $\mathrm{Al}_{2} \mathrm{O}_{3}$, peregangan pada patah sedikit meningkat. Menurut F. Mirjali dkk. (2009) semakin tinggi tingkat homogenitasnya maka kekuatannya juga semakin baik. Karena pendistribusian filler tidak merata dan terkonsentrasi pada beberapa tempat saja maka akan terbentuk ikatan yang lemah, dan pada titik-titik terlemah ini yang menyebabkan spesimen mudah patah sedangkan patahan yang terjadi pada spesimen merupakan patahan getas (Budinski Keneth G., 2003). Semakin kaku material, maka semakin rendah pula persentase peregangan pada patah yang akan ditekan. Ini ditunjukkan pada penurunan daya kerusakan pada antar muka yang kaku antar fiber dan matrik. Penurunan pada peregangan patah menunjukkan keuletan Polypropylene yang sudah ditekan oleh adanya nano $\mathrm{Al}_{2} \mathrm{O}_{3}$. Modulus flexural nano $\mathrm{Al}_{2} \mathrm{O}_{3} /$ Polypropylene komposit menunjukkan susunan peningkatan yang sangat baik pada bidang-bidangnya, secara drastis akan meningkatkan nano $\mathrm{Al}_{2} \mathrm{O}_{3}$ hingga $2 \mathrm{wt} \%$ setelah sedikit menurunkan beban nano $\mathrm{Al}_{2} \mathrm{O}_{3}$ dan kemudian memperbaiki beban nano $\mathrm{Al}_{2} \mathrm{O}_{3}$ hingga 3 sampai 7 wt\%. Menurut Malcolm (2005) bahan yang tidak dapat dicampur memiliki gaya tarik fisis antar bahan pembentuknya yang lemah pada batas komposisi tertentu, tetapi pada batas komposisi tertentu pula bahan komposit ini memiliki gaya tarik fisis antar bahan pembentuknya yang kuat sehingga bahan tersebut menjadi lebih ulet dan keras. Penurunan nilai kekuatan dan modulus flexural karena struktur non homogenitas campuran dan keberadaan antar muka ikatan yang lemah antara nano $\mathrm{Al}_{2} \mathrm{O}_{3}$ di sekitar matrik.

\section{SIMPULAN}

Hasil penelitian dengan penambahan partikel nanopartikel alumina yang dicampurkan kedalam matrik bijih plastik Polypropylene hasil daur ulang dengan proses injection moulding menunjukkan bahwa kekuatan tarik, modulus elastisitas dan peregangan(elongation) menurun ketika dengan penambahan sampai $2 \%$ dan mengalami peningkatan ketika prosentase nanoalumina meningkat di atas $2 \%$ hingga sampai $7 \%$.

\section{DAFTAR PUSTAKA}

Arumaarifu. 2010. Apa itu komposit [Diakses 02 April 2010] arumaarifu.wordpress.com

Budinski Keneth G. 2003. Engineering Material Properties and Selection, Prentice Hall, New Jersey

Edy Dwi Cahyono. 1996. "Proseding Pemaparan Hasil Hibah IPTEK, Bandung, 14-16 Oktober

F. Mirjali, dkk. 2009. Mechanical properties of $\alpha-\mathrm{Al}_{2} \mathrm{O}_{3} /$ PP nano composite. journal of applied Sci. 9(17): 3199-301.

Hajrianto, Feri F. 2005. Limbah Plastic, jenis dan kemungkinan pemanfaatnya untuk aplikasi bahan teknik. Jogyakarta

Hosen J., 2001. Polimerisasi, Pemrosesan Produk Plastik berbasis Polyester. ITB Bandung

http://www.indonetwork.co.id/sell/kimia/0.html

http://www.pu.go.id/balitbang/puskim/protek_kim/ttg_kim_ 27070/ttg_kim_ppsp_htm

Malcolm.P.S. 2005. Kimia polimer. Pradnya paramita. Jakarta

Nurul T. 2006. Nano teknologi di Indonesia peluang dan tantangan. LIPI Jakarta

Yang, H.S., Kim, H.J., Son, J., Park, H.J., Lee, B.J \& Hwang, T.S. 2004. Rice Husk Flour Filled Polyprophylene Composites; Mechanical and Morphological Study. Compos Struc. 63, 305-312

Wu, C.L, MQ. Zheng M.Z. Rong and K. Frederick. 2002. Tensile performance improvement of low nanoparticles filler-polypropelene composites comp. Sci. technol. 62-1327-1340. 